\title{
OPTIMIZATION OF CROSSPIECE OF WASHING MACHINE
}

\author{
Sunil Patil ${ }^{1}$, S. A. Kulkarni ${ }^{2}$ \\ ${ }^{1,2}$ Mechanical Engineering Department, Sinhgad College of Engineering, Pune, Maharashtra, India
}

\begin{abstract}
The Optimization through FEA is new emerging field. Now a day's providing product with less cost and with good functioning becomes necessary due to high competitions in market. Nowadays it is very necessary to shorten the development process of new components. Therefore tools are necessary that replace the natural evolution process by an automatic procedure. With today's available resources the optimization approach is the best approach for industrial components which are having large number of design variables with more than one objective to satisfy. This paper includes optimization of crosspiece of washing machine by using FEA concept. One simple component is taken to correlate optimization FEA results with practical results. After validating simulation results of optimization, industrial component crosspiece of washing machine with drum assembly is considered for optimization. The material reduction objective is satisfied here by using simulation software tools like Optistruct, Hypermesh, Hyper view. The output shape from optistruct is converted into manufacturable part. Again simulation testing is performed for static loading. At last results before optimization and after optimization are compared for crosspiece.
\end{abstract}

\section{INTRODUCTION:}

Optimization of an engineering design is an improvement of a proposed design that results in the best properties for minimum cost. Now a days due to competitive environment, it is necessary to producing more efficient designs having maximum margin of safety, Reducing production cost, Speeding design procedure, Correlating test data and analysis results. Optimization by using FEA concept is the best way to achieve optimized part.

Optimization can be defined as the automatic process to make a system or component as good as possible based on an objective function and subject to certain design constraints. A basic goal of design optimization is to automate the design process by using a rational, mathematical approach to yield improved designs. Optimization seeks to minimize or maximize the objective function (f) subject to the constraints $\left(\mathrm{g}_{\mathrm{j}}\right)$ defined.

$\mathrm{F}=$ a minimum $/$ maximum w.r.t $\eta_{\mathrm{i}}$

Subject to

$0<\eta_{i} \leq 1 \quad(\mathrm{i}=1,2,3, \ldots \ldots \ldots \ldots \mathrm{N})$

$\mathrm{f}_{\mathrm{j}}<\mathrm{g}_{\mathrm{j}} \leq \mathrm{h}_{\mathrm{j}} \quad(\mathrm{j}=1,2,3, \ldots \ldots . \mathrm{M})$

Where,

$\mathrm{N}=$ number of elements

$\mathrm{M}=$ number of constraints

$f_{j}=$ computed $j^{\text {th }}$ constraint value

$\mathrm{g}_{\mathrm{j}}=$ lower bound for $\mathrm{j}^{\text {th }}$ constraint

$\mathrm{h}_{\mathrm{j}}=$ upper bound for $\mathrm{j}^{\text {th }}$ constraint

Optimization process requires knowledge about the stage of design, design variables and their minimum and maximum limits (independent variables), constraints, measurement of the design performance (dependent variables), design parameters and relationships between the independent and dependent variables (i.e. a design evaluation model). The design variables are dependent on the level of product definition available at the different stages of the design optimization. The design stages can vary from conceptual or preliminary design, and from configuration to detailed design. Design variables are expressed in either quantitative or qualitative terms. The nature of the model development will vary depending on the types of the variables. Each variable is given a minimum and maximum value, to reduce the possible choices for a design, called as bounds of the variable.

\section{EXPERIMENTAL VALIDATION:}

Simple plate is considered initially to understand complete procedure of optimization so that it will help in validating results obtained from software and practical test. Steps of optimization by using FEA software are

Step 1-3D modeling of part

Step 2- FEA modeling of part

Step 3- Static simulation of present part

Step 4- Optimization of part by FEA software

Step 5- Validating analysis results with practical test results.

3D modeling of sample plate is done with help of Pro-E software and used as reference surface to generate FEA model in Hypermesh. It is analyzed for static loading to get maximum deflection of plate. Topography optimization is performed with objective of controlling maximum deflection of plate. Now this angle plate set for topography optimization, with objective as static displacement and constraint as maximum deflection at particular area should not exceed 7.0 
$\mathrm{mm}$ with thickness of angle plate as $0.5 \mathrm{~mm}$. Angle plate areas is converted into design space area and not design space area as per requirement. The form shape is only applied at design space area. Non-design space area remains unaltered while optimization. The same meshed model for static simulation is further used with design space and non-design space. The preprocessing is performed in Hypermesh software using optistruct environment and for solving FEA model Optistruct is used.

The objective and design variables are as below.

Objective,

Minimize static displacement

Variables, Step1

Step2
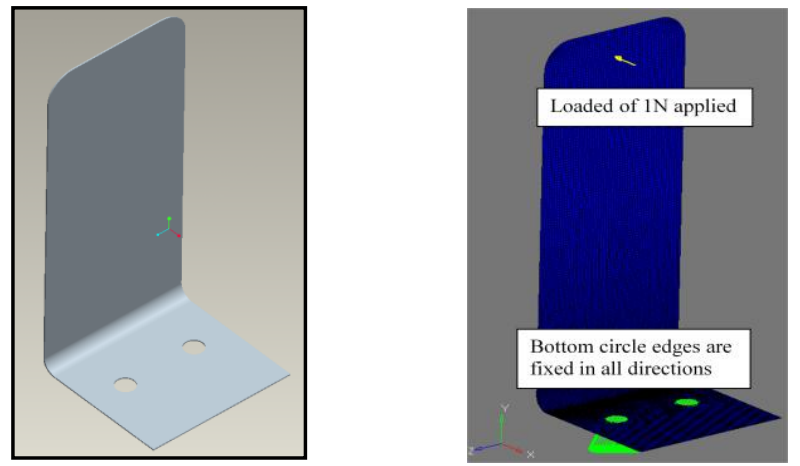

Step4

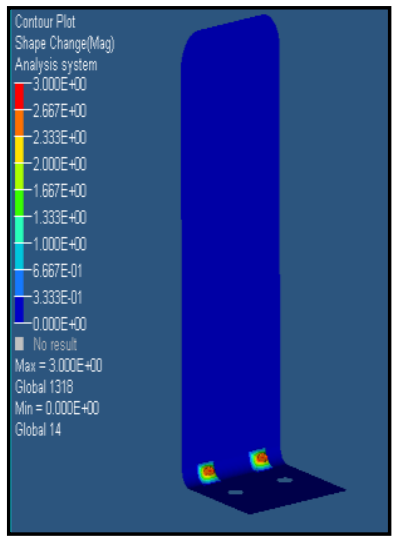

\begin{tabular}{|l|l|l|}
\hline & $\begin{array}{l}\text { Maximum } \\
\text { Displacement with } \\
\text { Simulation Results }\end{array}$ & $\begin{array}{l}\text { Maximum } \\
\text { Displacement with } \\
\text { Practical Results }\end{array}$ \\
\hline $\begin{array}{l}\text { Original angle plate } \\
\text { with thickness of } \\
0.50 \mathrm{~mm}\end{array}$ & $8.1 \mathrm{~mm}$ & $8.0 \mathrm{~mm}$ \\
\hline $\begin{array}{l}\text { Optimized angle plate } \\
\text { with form shape and } \\
\text { thickness of } 0.50 \mathrm{~mm}\end{array}$ & $7.0 \mathrm{~mm}$ & $7.0 \mathrm{~mm}$ \\
\hline
\end{tabular}

Fig.1 Steps followed in Experimental validation
Minimum width $>10 \mathrm{~mm}$

Draw angle $=60$

Draw height $\leq 3 \mathrm{~mm}$

The optimization procedure is explained in detail with case study of angle plate. The static loading final result obtained by using FEA software and practical test are matching with each other. Thus it's proving that results obtained by FEA method using Optistruct solver are correct.

After validating simulation result and practical result with respect to angle plate, industrial component crosspiece of washing machine is considered for next step.

Step3

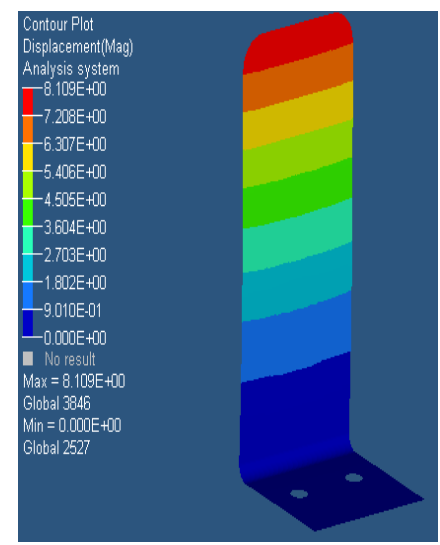

Step5

\section{OPTIMIZATION OF CROSSPIECE OF}

\section{WASHING MACHINE:}

The industrial product crosspiece of washing machine is considered here for performing optimization with objective of reducing mass of part. The crosspiece is the part which supports drum assembly of washing machine. The torque inputs from motor are transferred to drum assembly through crosspiece. For front loading washing machine the bending 
load will be there due to drum assembly weight and clothes loading in drum.
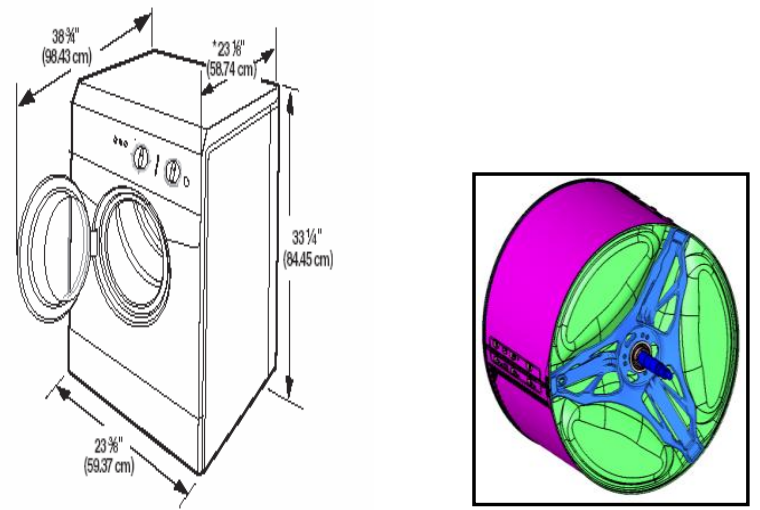

Fig. 2 Drum assembly of washing machine with present crosspiece

With respect to assembly constraints and design constraints proposed design of crosspiece with drum assembly is shown below. Initial crosspiece with filled material is considered.

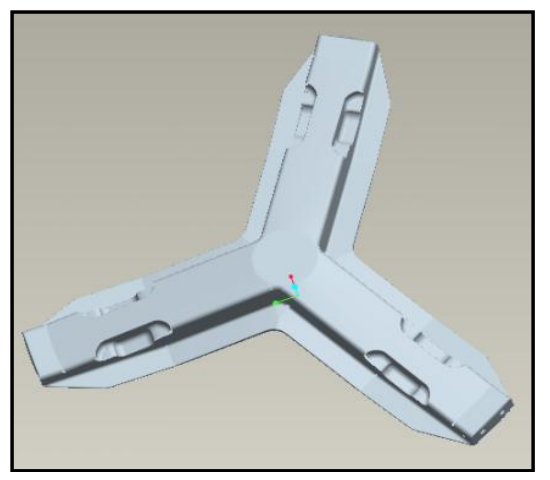

Fig. 3 Proposed crosspiece Baseline shape

\section{Objective Function:}

- Minimize the volume fraction response.

\section{Constraint Functions:}

- 1 constraint function specifying that the response cannot deflect more than $2 \mathrm{~mm}$ using the 1 load step.

- 1 constraint function specifying that the response cannot be more than $0.05 \mathrm{~N}-\mathrm{MM}$ using the 1 load step.

\section{Manufacturing Constraints:}

- Draw Split direction constraints are applied

- Pattern grouping of cyclic 1point symmetry is used.

\section{Responses:}

- 1 response for the total displacement of a node on two of the six screw holes.
- 1 response for volume fraction.

\subsection{Boundary and loading conditions for analysis:}

- Constrained at shaft mounting in all directions

- Unbalanced force of $2018 \mathrm{~N}$ is applied in vertical direction

- Unbalanced moment of $35 \mathrm{Nm}$ is applied about rotational axis

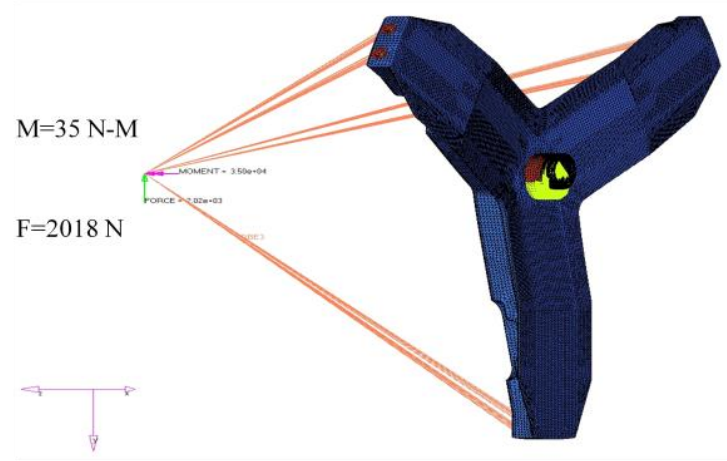

Non design Area

Design Area

Fig.4 Boundary and loading conditions

\subsection{Material properties to be used for analysis:}

\begin{tabular}{|l|l|l|l|}
\hline Part. No. & $\begin{array}{l}\text { Material } \\
\text { name }\end{array}$ & $\begin{array}{l}\text { Young's } \\
\text { Modulus } \\
\text { MPa or } \\
\text { N/mm2 }\end{array}$ & $\begin{array}{l}\text { Poisson's } \\
\text { ratio }\end{array}$ \\
\hline W10202465_P1.prt & Aluminum & $0.7 \mathrm{e} 5$ & 0.3 \\
\hline
\end{tabular}

With above boundary and loading conditions, crosspiece is solved for optimization with the help of Optistruct solver. The material density supporting for given loading and boundary conditions is shown below. 


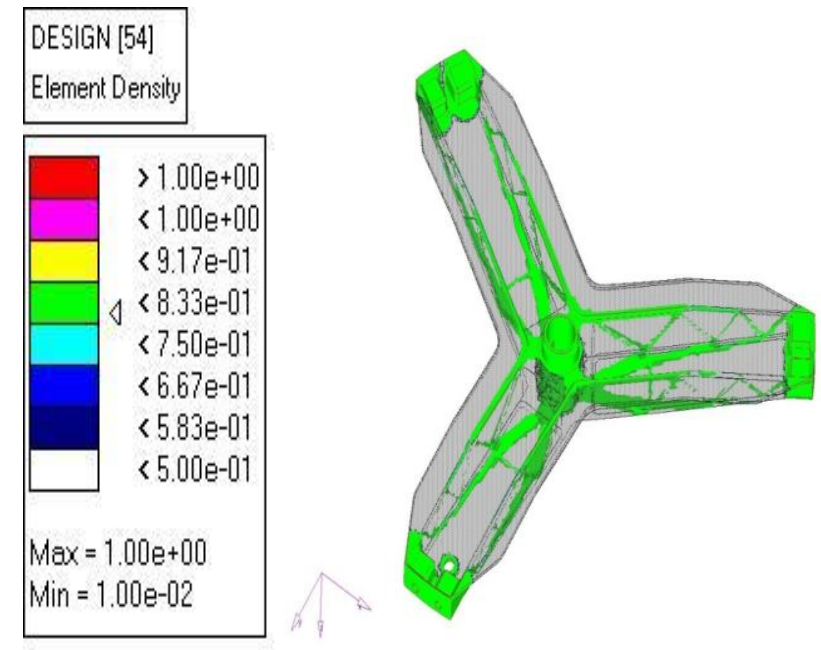

Fig.5 Density plot of crosspiece

To get manufacturable optimized shape of crosspiece many more iteration are performed and final proposed crosspiece is shown below.

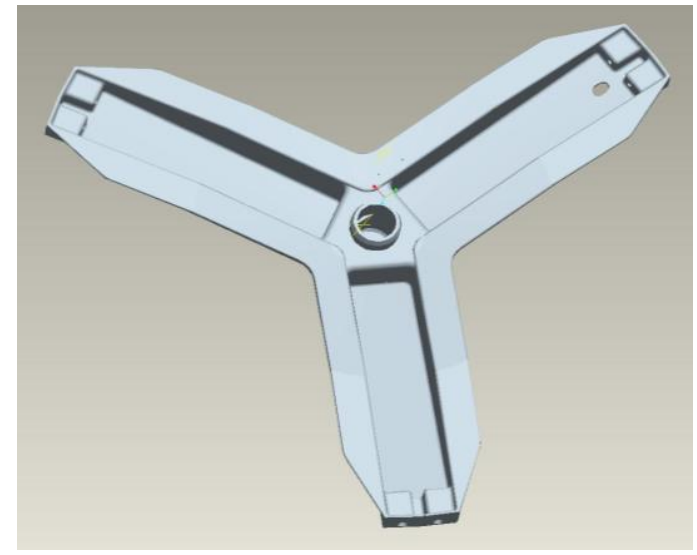

Fig.6 Final design of crosspiece

The present crosspiece is having weight of $1.5 \mathrm{~kg}$ and final optimized crosspiece is having weight of $1.3 \mathrm{~kg}$. Thus there is $0.2 \mathrm{~kg}$ amount of material saving. Maximum deflection of the crosspiece is $1.2 \mathrm{~mm}$ which is within acceptable limit. The static simulation of crosspiece shown that optimized cross piece is safe in required operating conditions. Also final part obtained after optimization is easy to manufacture compare to present one.

\section{CONCLUSIONS}

The static loading final result obtained by using FEA software and practical test are matching with each other. Thus it's proving that results obtained by FEA method using Optistruct solver are correct. The cost and time involved in prototyping of crosspiece is saved and project is completed within specified time range.

Optimization of component with the help of Finite Element Analysis is better and less time consuming process from present available methods. Software like Optistruct, Ls-Opti are well capable of handing complex structural parts for optimization. Quick and better designing of parts is possible with optimization.

\section{REFERENCES}

[1] S. S. Rao, "Engineering optimization: theory and practice", Wiley-IEEE, 1996.

[2] Omar Al Jadaan, Lakishmi Rajamani, C. R. Rao, "Non-dominated ranked genetic algorithm for solving multi-objective optimization problemsL:NRGA", Prof., Department of CIS, University of Hyderabad, Hyderabad500-046, INDIA,2008.

[3] Tushar Goel, Nielen Stander "Multi-Objective Optimization Using LS-OPT", Livermore Software Technology Corporation, Livermore, CA, USA,2007

[4] Abdullah Konak, David W. Coit, Alice E. Smith "Multi-objective optimization qusing genetic algorithms: A tutorial", Information Sciences and Technology, Penn State Berks, USA,2006.

[5] J.F. Aguilar Madeira, H. Rodrigues, Heitor Pina. "Multi-objective optimization of structures topology by genetic algorithms", ISEL-Instituto Superior de Engenharia de Lisboa, Lisbon, Portugal, 2004. 